\title{
InnovaRig - The New Scientific Land Drilling Facility
}

\author{
by Lothar Wohlgemuth, Ulrich Harms, and Jürgen Binder
}

doi:10.2204/iodp.sd.5.12.2007

\section{Introduction}

Deep drilling is becoming an increasingly important tool to study fundamental processes at depth, such as earthquake nucleation in fault zones or volcanic structures and eruption mechanisms or other basic Earth science research topics. At the same time, there are growing demands for new sustainable energy sources (e.g., geothermal energy) and for underground storage of carbon dioxide. Drilling for such missions often takes place in unexplored, structurally or geotechnically difficult environments that require special drilling, coring, and testing capabilities. Furthermore, continuous coring, deviated drilling, and complex testing are frequently required within these kinds of research projects. However, the worldwide market for drilling devices appropriate for this is small and currently is stressed by very high hydrocarbon exploration activity. Accordingly, scientific projects are often unable to contract the right drilling rig and service, or cannot get it for the planned timeframe or at an affordable price.

Several projects in the framework of the International Continental Scientific Drilling Program (ICDP) were severely hampered by the fact that suitable rigs were not available or that they did not have the capability or the flexibility for various drilling, coring, or testing options necessary for scientific operations. For ICDP and other projects the GeoForschungsZentrum Potsdam therefore developed a new deep drilling and coring installation in cooperation with the company Herrenknecht GmbH in Schwanau (southern Germany). On 14 May 2007 the novel deep drilling and coring installation called InnovaRig was officially commissioned for a first operations test at the manufacturer's workshop (Fig. 1). From summer 2007 on, drilling of up to $5 \mathrm{~km}$ $(\sim 16,000 \mathrm{ft})$ depth can be realized through the derrick with a hook load of $3500 \mathrm{kN}$. One of the key features for scientific drilling in InnovaRig is that it allows for fast changes from rotary drilling to wireline diamond coring or vice versa in order to sample key lithologies and switch to faster and inexpensive rotary drilling in less important geological sections.

The Helmholtz Association of German Research Centers funded the development of the facility that is owned by the GFZ and will be made available for scientific and industrial projects through a commercial operator (Geoforschungsboh rgesellschaft). The contractual basis for this arrangement is designed to allow for industry missions during pauses between scientific drilling projects, thus avoiding costly standstill (or a need for permanent scientifically funded operations). For this reason the InnovaRig has been designed to be technologically and economically attractive for industry purposes as well. For scientific drilling projects, the day rates charged will not include depreciation of investment costs.

\section{Technical Characteristics}

In the InnovaRig, the usual standard of a rope hoist carrying the drillstring or casings is replaced by a hydraulic cylinder drawworks with $22 \mathrm{~m}$ stroke. Drill pipe is handled using "hand-off technologies" with semi-automated connection of two pipes to one stand in a horizontal position in a bridge magazine outside the derrick, while a new type of pipe handler transports stands into the tower from a horizontal magnetic pipe racking system on ground. The pipe handler provides practically unlimited capacity and does not compromise working on the rig floor due to setback areas. All kinds of pipe and casing in sizes between $27 / 8$ " and 241/2" can be handled in the system with tripping speeds of up to $500 \mathrm{~m} \mathrm{~h}^{-1}$. The drillstring is driven by two separate top-drive

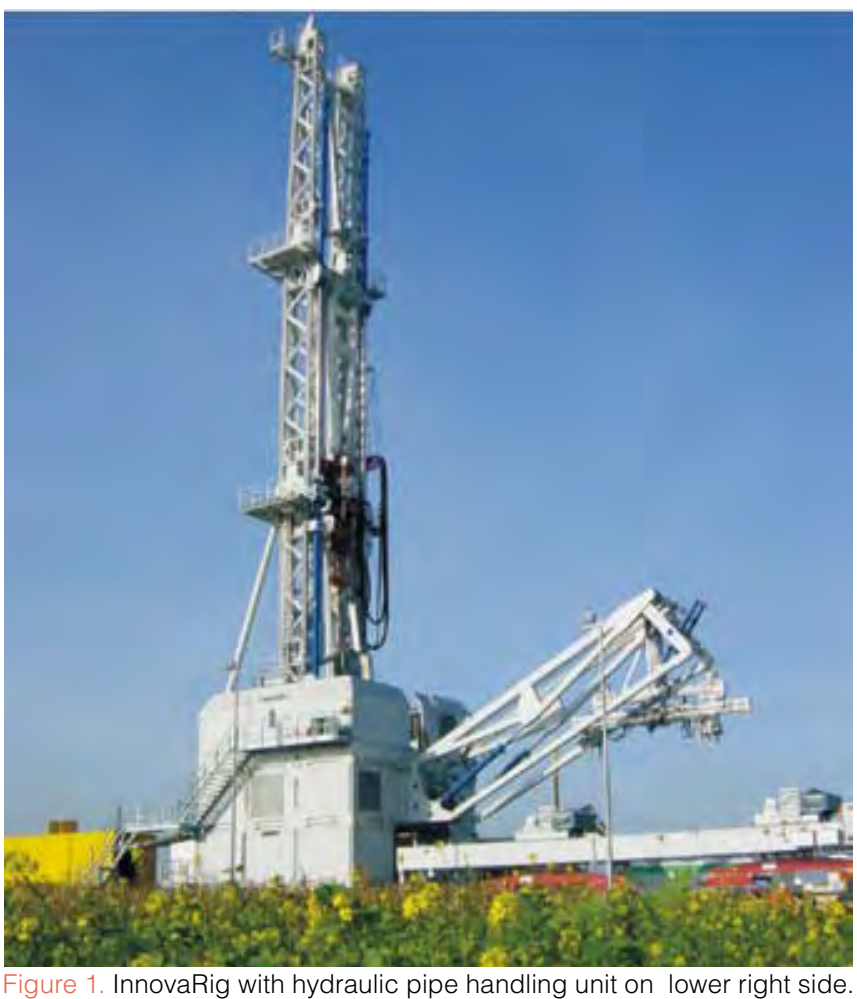
Photo by Herrenknecht Vertical. 
systems with a broad range of rotary speeds and an auxiliary rotary table. Furthermore, the mud system, tanks, and pumps are constructed to be flexible for adapting to the various drilling procedures. The complete system including rig with pipe handler, pumps, mud tanks and other equipment can be skidded for easy relocation during multiple well operations.

The design and construction of the complete InnovaRig were performed to achieve a maximum potential for fast, inexpensive operations without any negative effects on efficiency, safety, and the environment. Key features (see Table 1 for details) are:

- the modular set-up and complete containerization which allow rapid conversion, mobilization, and skidding,

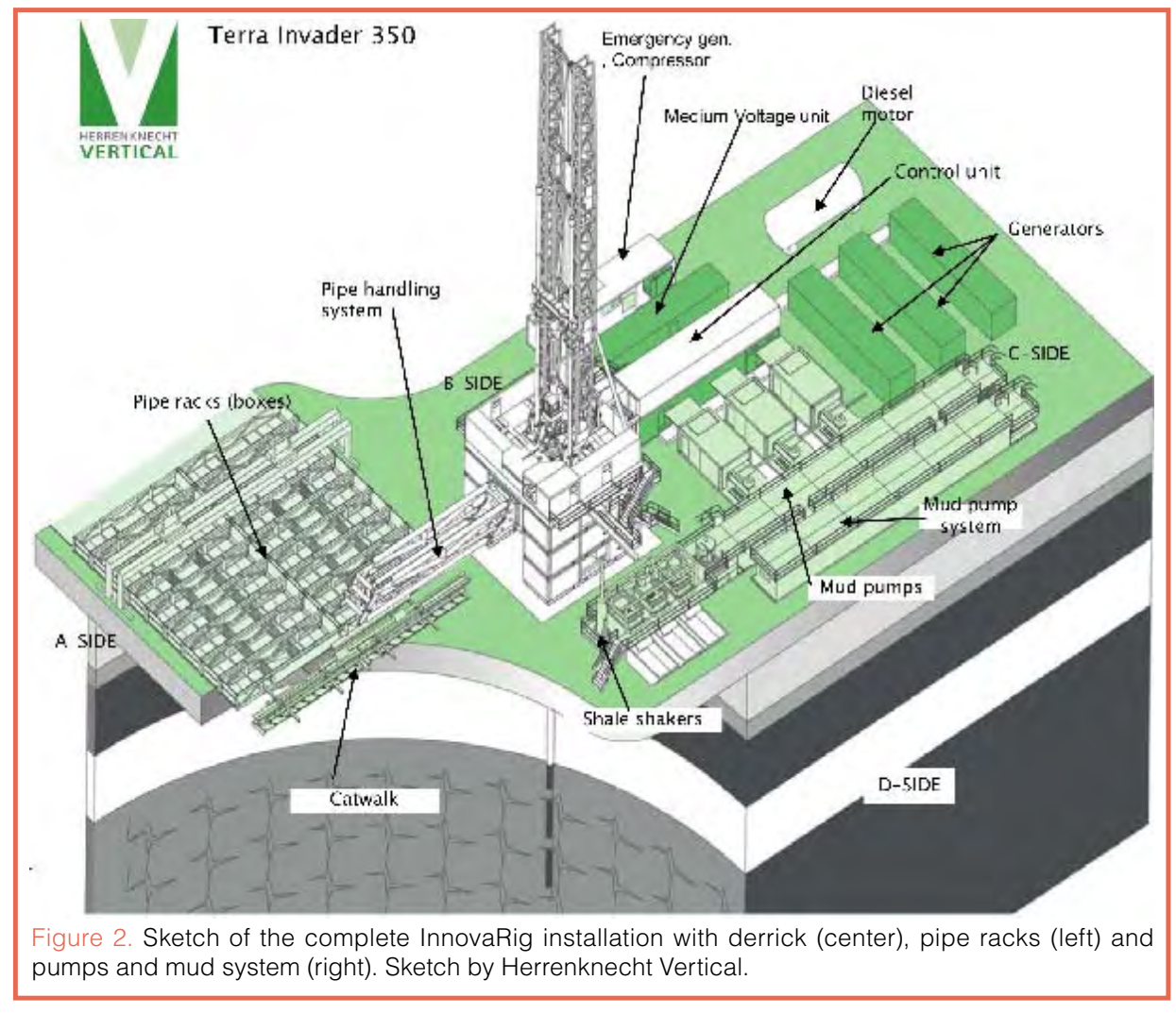

- $\quad$ the ability to rapidly switch between various drilling options including airlift drilling in large diameters (0-500 m depths), standard rotary drilling, continuous wireline diamond drilling, casing drilling as well as underbalanced drilling,

- the high degree of automation, in particular the semi-automatic pipe-handling for safe operations, condensed rig workload, and a minimum staffing,

- the high integration of devices for scientific measurements and tests to allow for a very fast switch from drilling to science operations,

- $\quad$ the minimization of area required for the drill site and the project-dependent use of rig modules, and

- the option to use either public or rig-installed power sources.

In terms of energy consumption and environment protection, InnovaRig can be operated through internal and/or public power supply, with biodegradable mud additives and greases. The rig is fully shielded against noise to allow deployments close to housing areas and will be extended for almost "waste-free" operations. In addition to standard equipment for rotary drilling such as $6.5-\mathrm{km}$ drillstring and heavy pipes, the facility is outfitted with $5.5-\mathrm{km}$ wireline pipes plus coring system and winch, 1000 -m pipes for airlift drilling, as well as a 10,000 psi blowout preventer. In the case of low diameter wireline drilling in mining dimensions, the mud flow system can be easily rescaled to the volume of the circulating drilling fluid.
An important restriction is that although the rig can be partly downsized, it is a really heavy piece of equipment (Figs. 1 and 2) whose mobilization costs for more than 60 truckloads and day rates will not be suitable for shallow borings to less than $\sim 2 \mathrm{~km}$ depth.

\section{Special Installations for Science Operations}

Geophysical wireline logging tools need to be deployed in research wells on short notice without lengthy backfitting. Accordingly, InnovaRig has cable guidance, sonde racks, spaces for winches, etc. integrated and in easy reach. At any time during drilling, the working platform is clear for setting up and recording wireline logs or conducting experiments such as vertical seismic profiling.

To allow a regular automatic sampling of drill chips, a sampling facility for cuttings and drill mud is provided at the mud cleaning line. This is extremely useful during noncoring phases to determine a couple of important parameters of the drilled rock column. In addition, mud samples can also be used to determine formation fluid inflow zones at depth which change the ion load in the drilling fluid. A mud gas extraction unit is also integrated to assure air contamination-free analysis of gaseous components from drilled rocks in the mud. Tracers or reference gases can be injected into the well during drilling operations through extra pipes flanged to the injection pumps. Such devices can, for example, be used to determine the lag time of the mud circulation and thereby detect the location of inflows. 


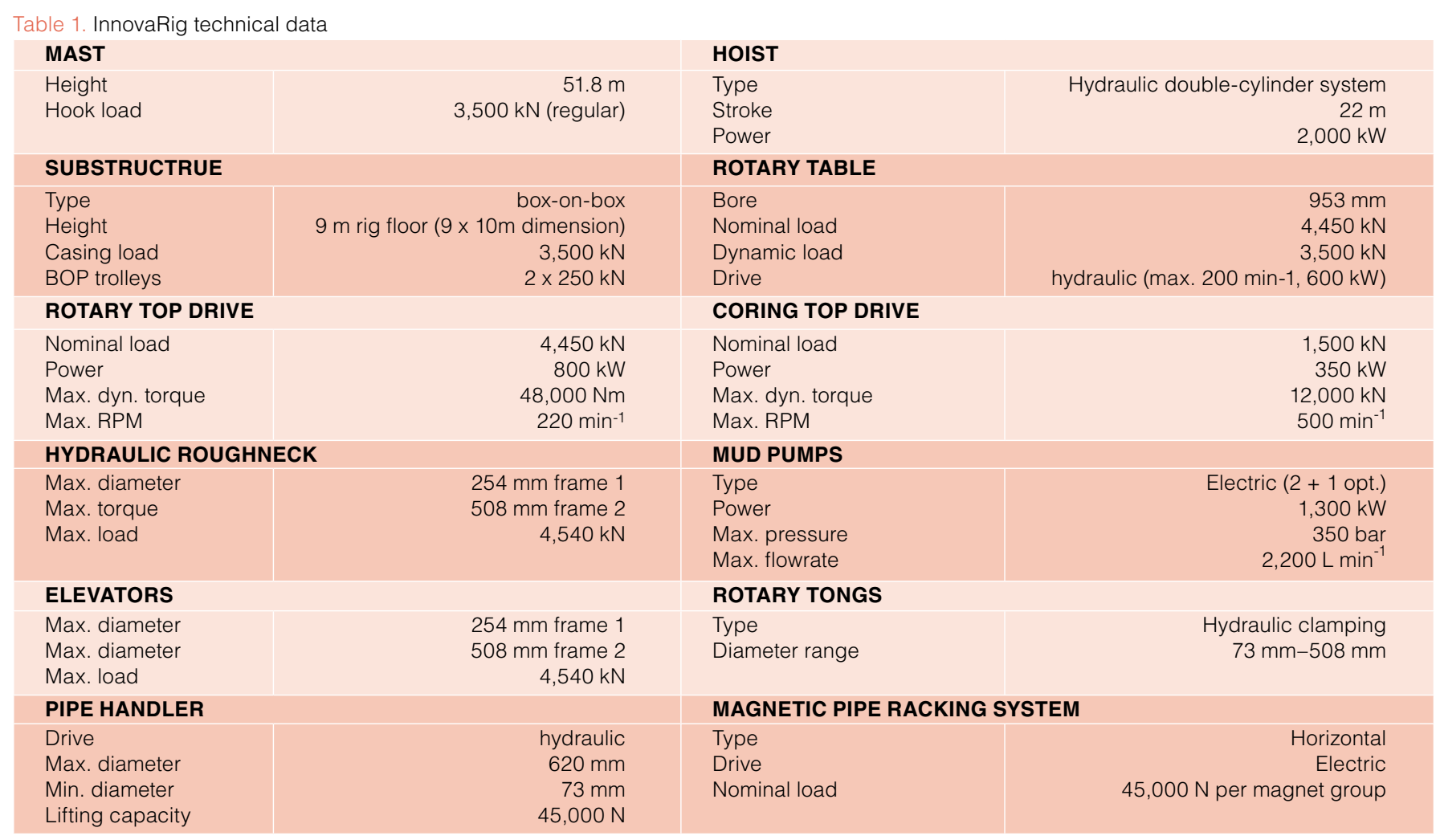

Science containers, such as a core and cuttings lab, a microbiology unit, or a containerized geochemistry lab, have extra space with power, water, and communication hook-up reserved within the setup of the drill site. The integrated data acquisition system records rig parameters, drilling data, and scientific data according to project needs. All these data are captured through a central bus system and stored in the systems main computer that offers direct connections to other data banks and Internet, and it is capable of handing over all data directly to the ICDP's Drilling Information System, DIS (Conze et al., 2007).

\section{Outlook}

The implementation of the idea to produce and operate a novel "science-owned" type of deep land drilling facility is a new pathway in scientific drilling, since land drilling endeavors are usually performed with contracted service rigs of opportunity. However, the lack (or at best, the very high costs) of suitable tools on the world market advanced this development. As it is anticipated that there will be no continuous science operations for this tool, neither within ICDP nor in other research-related drilling projects, InnovaRig will be operated on an as-needed basis also for industry. Scientific projects will have priorities, but commercial missions will be performed as long as no research project is being conducted.

Due to its outstanding, novel capabilities, InnovaRig can be used now in a very broad range of deep drilling missions for research and in industry projects. In terms of engineering, the facility is expected to establish a modern, inexpensive standard with hydraulic drive and pipe handling, as well as variable drilling capabilities. For science, the tool will provide the long-needed flexibility for coring, whenever necessary and useful, convenient installations for research without costly conversions. For these reasons, Innova Rig will support advancing Earth sciences with drilling projects.

The first deployment will be performed during this summer for a commercial 4-km-deep geothermal drilling project in southern Germany. Further applications are not yet contracted, but negotiations for the use in ICDP and in further geothermal research projects are currently underway. Proposals for the use of the InnovaRig are welcome.

\section{References}

Conze, R., Wallrabe-Adams, H.J., Graham, C., and Krysiak, F., 2007. Joint data management on ICDP and IODP mission specific platform expeditions. Sci. Drill., 4:32-34.

\section{Authors}

Lothar Wohlgemuth and Ulrich Harms, Operational Support Group ICDP, GFZ Potsdam, Telegrafenberg A34, 14473 Potsdam, Germany, e-mail: wohlgem@gfz-potsdam.de. Jürgen Binder, Herrenknecht Vertical GmbH, 77963 Schwanau, Germany.

\section{Related Web Links}

www.icdp-online.org

www.vertical-herrenknecht.de 